\title{
AC 2011-2780: BOOTSTRAPPING A NEW GRADUATE CURRICULUM THROUGH AN ENGINEERING RESEARCH CENTER
}

\author{
Devdas M. Pai, North Carolina A\&T State University (Eng)
}

Devdas M. Pai is a Professor of Mechanical Engineering and serves as Director for Education and Outreach for the NSF Engineering Research Center for Revolutionizing Metallic Biomaterials. His research and teaching interests are in the areas of manufacturing processes and materials engineering.

\section{Robin Guill Liles, North Carolina A\&T State University}

Robin Guill Liles is associate professor in counseling and counselor education in the Department of Human Development and Services in the School of Education at North Carolina Agricultural and Technical State University, Greensboro. Liles is a Licensed Professional Counselor and National Certified Counselor. Liles' is also Associate Director for Educational Assessment for the NCA\&T Engineering Research Center Education and Outreach program, and she is co-principal investigator for research on the NSF Content Mentoring of Middle Grade Math and Science Teachers research study. Her teaching interests include assessment and appraisal, instrument construction, education research methodology, and research ethics.

Courtney Lambeth

Prashant N. Kumta, University of Pittsburgh

Harvey S. Borovetz, University of Pittsburgh

Sarah K. Pixley, Univ. of Cincinnati Coll. of Med.

Partha Roy, University of Pittsburgh

Dr. Roy is an Associate Professor of Bioengineering and Pathology at University of Pittsburgh. Dr. Roy obtained his $\mathrm{PhD}$ in Bioengineering from the University of Texas Southwetern Medical Center, Dallas and post-doctoral training in cell bioogy at Harvard Medical School and University of North Carolina, Chapel Hill prior to joining University of Pittsburgh. His main research interests are cytoskeleton and cell migration, tumor invasion/metastasis, angiogenesis, phosphoinositide signaling and protein-protein interactions.

Jagannathan Sankar

(C)American Society for Engineering Education, 2011 


\title{
Bootstrapping a New Graduate Curriculum through an Engineering Research Center
}

\begin{abstract}
NSF Generation-3 Engineering Research Centers (ERCs) are charged both with advancing the state-of-the-art in terms of engineering and scientific research as well as training a well-qualified workforce in the domain of expertise. Such an ERC was awarded in 2008 to North Carolina A\&T State University (NCAT), with the University of Pittsburgh (Pitt) and the University of Cincinnati (UC) as the core US research partner institutions. The focus of this ERC, the ERC for Revolutionizing Metallic Biomaterials (RMB) is the development of advanced materials and processes targeted at the biomedical implant and device industry. NCAT has strong research and education programs in its mechanical, industrial, chemical and electrical engineering department, but it is the two other core research partner schools that brought in strengths in biomedical engineering and biomaterials. The challenge, then, was to bootstrap graduate instruction at NCAT by offering key courses that could quickly bring students up to speed in the concepts required to transition from engineered materials research to biomaterials research. This paper discusses the authors' experience with the first two of those courses that resulted.
\end{abstract}

\section{Background}

The research focus of the ERC-RMB is advanced biomaterials for use in implants and other biomedical devices. Our ERC's research theme is to produce innovative biodegradable metallic alloys and appropriate sensing technology for use in biomedical implant and other device applications. The team builds on distinct and complementary technical strengths of the core partners: materials engineering and nanotechnology at NCAT, bioengineering and materials science at Pitt, and corrosion science, sensor development and medical science at UC.

NCAT has baccalaureate through doctoral degree programs in mechanical, industrial and electrical engineering, and bachelor's through master's programs in other engineering disciplines. In the past, NCAT did not have any degree offerings in the bioengineering domain. One of the overarching educational promises of the ERC-RMB was to leverage the complementary strengths of the partners to aid in the eventual development of a continuum of undergraduate, master's and doctoral degree programs in bioengineering at the lead institution. Pitt and UC have long-standing and vibrant bioengineering degree programs. Further, the ERC has developed global research collaboration with the Hannover Medical School (MHH) in Hannover, Germany, and a global education partnership with the Indian Institute of Technology Madras (IITM) in Chennai, India.

As with all Gen-3 ERCs, the goal is to combine fundamental research and education while focusing on innovation. This would include collaboration with small firms that engage in translational research as well as international research partners, thus serving to prepare its students for success in an increasingly complex and integrated international economy. The goal 
is to produce graduates equipped with experience in interdisciplinary, inter-institutional and cross-cultural research and education who are able to define pathways to explore and realize innovation opportunities for success in both their immediate and global communities. The global partnerships greatly support the latter goal.

Since its inception in 2008, our ERC has been systematically developing a set of graduate courses co-taught by faculty at all three US partner institutions, to allow for effective pooling of resources as well as trans-institution academic interactions between faculty and students. Two graduate courses were taught during the 2009-2010 academic year. The first course, offered in Fall 2009, was on cell and molecular biology and the second one, offered in Spring 2010 was on biodegradable metals and metallic alloys. The following section elaborates on the curricular content and logistics of these courses. This is followed up with course effectiveness assessment data. This paper will discuss the initiatives adopted, challenges overcome and the assessment outcomes for these first trans-ERC courses.

\section{Course I: Cell Biology (Fall 2009)}

This course was offered with the same schedule at NCAT, Pitt and UC. Each school listed it with its own local title and course number. The course was cross-listed as follows: NCAT: MEEN 785.002 - Principles of Cell Biology for Engineers, Pitt: BIOE 2520 (Molecular Cell Biology and Biophysics I), and UC: Special Topics course in Mechanical Engineering. Each student was required to register in their home department. Each university took responsibility for the grading of its own student homework, term papers and exams based on keys/solutions provided by the lead instructor and a common letter grading scheme as well as grading scale were employed across the three campuses. Each campus maintained its separate course website on its course management system (Blackboard is used by all three schools). Each website contained links to course materials, so students only had to rely on campus IT resources without the need for access to the computer networks of partner campuses. About 45 students registered across the three campuses. Classes were held in distance learning classrooms at each school. Course broadcasting and web-archiving facilities were enabled through resources provided by Pitt's Bioengineering Department. The course met once a week for three hours. NCAT, whose engineering graduate students did not have any prior biology knowledge, were provided additional biology orientation by organizing a weekly recitation session staffed by qualified graduate students recruited from NCAT’s Department of Biology.

This course was led by one of this paper's authors (Roy), a professor in the bioengineering department at Pitt with an established track record of research in this field. It also had technical input from another author (Pixley), a medical school faculty member at UC, and guest lectures from other engineers and doctors at Pitt. Yet another author (Liles), an education faculty member at NCAT provided lectures on creativity and bioethics. This person also provided assessment services for this and other courses offered on a trans-ERC basis. The course deviated from a traditional cell biology course as would be offered by a biology department by emphasizing a lot of engineering aspects, including a quantitative study of optical microscopy and other characterization techniques. The course was enriched by links to sites specializing in research in some of the topics, for example FSU's microscopy website http://micro.magnet.fsu.edu/primer/index.html. Further, just-in-time visits to the biology labs at 
NCAT and the bioengineering research labs at Pitt and UC allowed students to relate their engineering fundamentals to the field use of microscopy and other characterization techniques for working with organic materials, tissues and even live animals.

Given the wide range of biology background preparation among ERC students across the three campuses, the pre-requisites for the course were kept very simple - undergraduate level physics and chemistry, with a course in organic chemistry being preferred. The textbook used was Bruce Alberts, Alexander Johnson, Julian Lewis, Martin Raff, Keith Roberts, Peter Walter: "Molecular Biology of the Cell" - Fifth Edition, Garland Science Textbooks, 2007. The course was described thus: "This is the first part of a 2-semester graduate course. Topics covered in this part of the course are basic cellular structures and tissue organization, protein biochemistry, protein techniques and regulation, membranes, microscopic techniques, genetics (chromatin organization, DNA replication, transcription, translation, control of gene expression and molecular biology techniques)". The course objectives were listed as: "The course will teach the principles of cell biology to students in the College of Engineering so you may perform interdisciplinary research in the area of cell biology. Research is becoming more crossdisciplinary and this course will help you work in the field of biology. The three principal course goals 1) to learn different macromolecules in cells, 2) to develop an understanding of the principles of cell structure and functions mainly focusing on fundamental genetic mechanisms, and 3) to learn the experimental tools used to understand cellular function such as molecular genetic techniques, biochemical analysis, and microscopy." Students were encouraged to further explore the use of the ERC research-focus material (magnesium) in biological applications through an extra-credit assignment. The engineering students from NCAT (Figure 1) also had the opportunity to attend a biomedical engineering research conference (BMES 2009) for the first time during their introductory course to cell biology and better able to directly relate classroom lectures to ongoing research.

\section{Assessment}

The assessment plan for this course included three components. The first component assessed student learning of MEEN 785.002: Principles of Cell Biology for Engineers content knowledge. The second component included evaluation of students' overall satisfaction with MEEN 785 teaching and learning. The third component included evaluation of students' overall

satisfaction with the hybrid class format. (A subset of this component involved assessment of student understanding of ways principles of cell biology link to concepts of creativity and innovation, diversity of thinking, and entrepreneurship.) IRB approval was obtained prior to collecting assessment data. The student distribution is found in Table 1 below.

Related to student learning of course content, there were three student learning outcomes as identified in the syllabus. These SLOs were:

- Students will learn different macromolecules in cells.

- Students will understand the different principles of cell structure and functions, mainly focusing on fundamental genetic mechanisms

- Students will learn about the experimental tools used to understand cellular function such as molecular genetic techniques, biochemical analysis, and microscopy. 
Table 1. Student distribution for class

MEEN 785: Principles of Cell Biology I for Engineers Student Distribution

Demographics

MEEN 785 Students

$(n=16)$

Gender

Females

6

Males

10

Race/Ethnicity

African American

8

Asian

8

Midway through the semester, MEEN 785: Principles of Cell Biology I for Engineers students $(n=12)$ were issued a survey gathering formative data related their growing understanding of course content and their opinions of course delivery. A review of these data suggests that generally students were "following" and enjoying course lectures and materials. A full example of one topic evaluation is found below.

Table 2. Mid-Semester Survey of MEEN 785: Principles of Cell Biology I for Engineers $(n=12)$

Part 1

Topic A: Cell structure (School C author)

\begin{tabular}{|l|l|l|l|l|l|}
\hline Aspect of topic coverage & $\begin{array}{l}\text { SD } \\
\text { (Strongly } \\
\text { Disagree) }\end{array}$ & $\begin{array}{l}\text { D } \\
\text { (Disagree) }\end{array}$ & $\begin{array}{l}\text { N } \\
\text { (Neutral) }\end{array}$ & $\begin{array}{l}\text { A } \\
\text { (Agree) }\end{array}$ & $\begin{array}{l}\text { SA } \\
\text { (Strongly } \\
\text { Agree) }\end{array}$ \\
\hline $\begin{array}{l}\text { Material was easy to } \\
\text { comprehend. }\end{array}$ & & 1 & 1 & 5 & 5 \\
\hline $\begin{array}{l}\text { Slides were clear and } \\
\text { adequate for study. }\end{array}$ & 1 & 1 & 2 & 8 \\
\hline $\begin{array}{l}\text { Verbal presentation was } \\
\text { clear: allowed } \\
\text { understanding of subject. }\end{array}$ & & & & 5 & 7 \\
\hline $\begin{array}{l}\text { Quiz/exam questions } \\
\text { related well to the lectures. }\end{array}$ & & 1 & 1 & 4 & 6 \\
\hline
\end{tabular}


Written comments to explain your reason for any of the above ratings will be very helpful:

a) Overall material was understood because we spent time on it.

b) Like the way the medical school author from School C designed slides for non-biology majors

c) The TA's helped a lot with the understanding of this section

d) The material I this section I found to be of ease. I do understand the complications of connecting this info to following section from an educators' point of view. The quiz and exams are based on this section and I don't believe enough emphasis is present in the lectures. Maybe this could be tweaked, so that the oral connects more with the slides and what we should have to know for our edification.

e) Great teacher! This is the most clear of all the lectures. After her explanation everything became clear, she made it more understandable and I didn't feel the need to memorize much.

Focus groups were also conducted at the end of the semester. A review of transcripts (descriptive data) provided the following information.

- Innovation and Creativity: Participants easily made connections among scientific discovery, innovation, and creativity. They placed emphasis on asking the right questions and looking in new ways to find the answers to those questions. Therefore, there is a clear connection with diversity of thinking and innovation and creativity.

- Diversity of Thinking: Participants repeatedly connected the concept of diversity of thinking with working in groups and particularly interdisciplinary collaborations. There is an emphasis on communication and sharing knowledge either through interaction or reviewing previous research.

- Entrepreneurship: Participants made the connection of entrepreneurship occurring when innovation fills a need in society that makes the product or service profitable. Some participants indicated that bioengineering is a possible area for entrepreneurship in the future.

- Multi-stage System: Participants were able to define multi-stage systems as an entity with multiple parts which work together to meet a specific goal. They were able to conceptualize this in multiple ways including the ERC and their own professional development.

\section{Course II: Biodegradable Metals (Spring 2010)}

Again, this course was offered with the same schedule at NCAT, Pitt and UC. Each school listed it with their own local title and course number. The course was cross-listed as follows: NCAT: MEEN 785.002 - Fundamental Principles of Biodegradable Metallic Alloys, Pitt: BIOE 2016 / CHE 2016 - same title, and UC: Special Topics course in Mechanical Engineering. Each student was required to register in their home department. Each school took responsibility for the grading of its own student homework, term papers and exams based on keys/solutions provided by the lead instructor and a common letter grading scheme as well as grading scale were employed across the three campuses. Each campus maintained its separate course website on its course management system (Blackboard is used by all three schools). About 20 students registered across the three campuses. Classes were held in distance learning classrooms at each school. Course broadcasting and web-archiving facilities were enabled 
through resources provided by Pitt's Bioengineering Department. The course met once a week for three hours. Given the engineering materials (specifically, metals) focus of this course, all the engineering students at NCAT, Pitt and UC were equally prepared. However, some background information had to be provided to graduate students who entered ERC research after obtaining non-engineering undergraduate degrees in fields such as biology or chemistry.

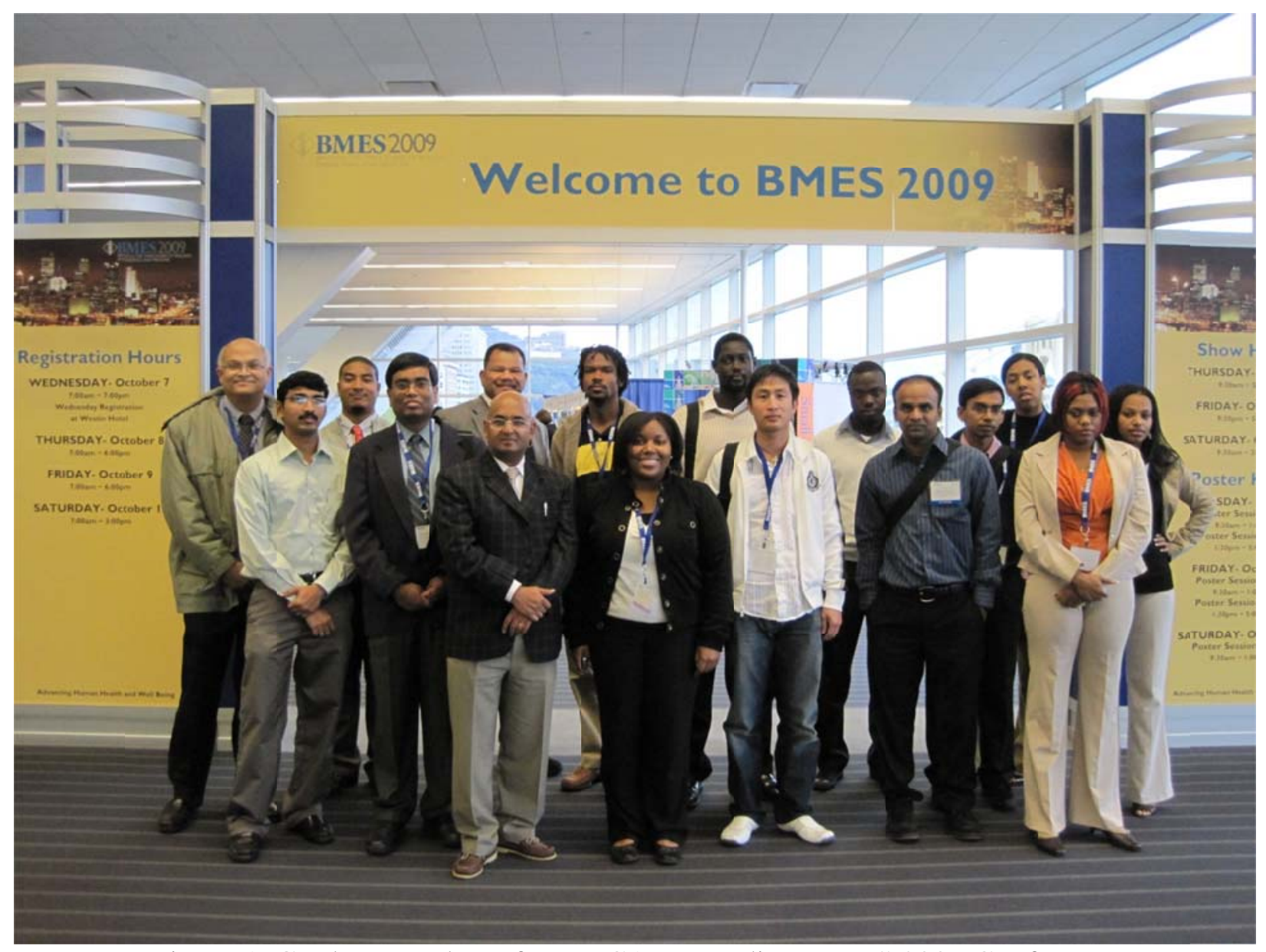

Figure 1. Graduate students from NCAT attending BMES 2009 Conference

This course was led by one of this paper's authors (Kumta), another professor in the bioengineering department at Pitt, but had guest lectures from medical and dental school faculty members at Pitt and from the medical faculty at $\mathrm{MHH}$, as well as by engineering faculty from NCAT and UC. Yet another author (Liles), an education faculty member at NCAT continued to provide lectures on creativity and bioethics. This person also provided assessment services for this and other courses offered on a trans-ERC basis. The course leader from Pitt also happens to lead the metal alloy design, processing and characterization research thrust of our ERC and some of the authors at other institutions collaborate with him on this topic and were natural sources for guest lectures. The course thus deviated from a traditional academic graduate course by directly relating the research being actually conducted in the labs by the self-same students to the underlying fundamentals being exposed in the lectures. The lead instructor deviated from traditional metallurgical textbooks by providing quantitative problems directly related to the use 
of metals in bioimplants, often using numbers and data that might have been collected by the instructor's graduate students.

Given the wide range of biology background preparation among ERC students across the three campuses, the pre-requisites for the course were kept very simple - undergraduate level courses in thermodynamics, with introductory courses in materials science and physiology being preferred. Given the relatively nascent stage of the research topic, no preferred textbook was available, but the instructor provided copious notes at the course Blackboard website. Suggested references included: 1) Biomaterials Science: An Introduction to Materials in Medicine, by Buddy Ratner (1996), 2) Biomaterials, Park and Lake, Plenum Press, 1992, 3) Biological Performance of Materials, Black, Marcel Dekker, 1992, 4) Principles of Tissue Engineering, R.P. Lanza, R. Langer, W.L. Chick, Academic Press (1997), 5) Biomedical Engineering Handbook, J.D. Bronzino, CRC Press (2000), 6) Elements of Materials Science and Engineering: Van Vlack, Addison Wesley (1989), 7) Handbook of Magnesium and its Alloys: Eds: Avedesian and Baker (1999). The course was advertised thus: "Biodegradable metals have emerged as a new class of materials with significant potential for myriad biological applications in particular, the craniofacial, orthopedics and cardiovascular areas. The latter has already witnessed clinical trials with few patients already being implanted with a biodegradable metallic stent. This course is designed to introduce the principles and various fundamental concepts of this novel class of metallic alloys. These include fundamental principles of metal alloy physics and theory, important concepts of phase diagrams, physical metallurgy concepts, metallic glass theory, processing fundamentals, biocompatibility, and toxicity issues. The effect of microstructure on biocompatibility and corrosion will also be discussed. The course objective is to introduce the student to this new family of bio-functional metals and their biodegradable properties. In doing so, the student will be familiar with these materials and their useful applications.” The following were the course goals set forth: "The principal goal of this lecture course is to introduce the fundamental concepts related to biodegradable metallic biomaterials, their properties and applications. Biodegradable metallic alloys are a relatively new concept that can potentially change the landscape of materials and their use in regenerative medicine. Materials can be broadly classified into three classes namely, metals, ceramics and polymers based on the individual components and the nature of the bonding. This course will primarily emphasize the structure, properties and biological applications of metallic materials. The course will therefore begin by providing an introduction to materials and will commence by describing metallic systems, the primary applications of metallic biomaterials. This will be followed by highlighted studies related to principal non degradable and biodegradable metallic materials used as replacement for hard and soft tissue replacement. Important fundamental aspects of materials, structure, phase relations, microstructure, structural properties and characterization will then be introduced. The interaction of materials with tissue will be discussed and relevant concepts of physiology, cells, tissue and protein structure and properties will be discussed. Lastly, the course will highlight relevant case studies of biodegradable metallic alloys used in the body as replacement or implants.” 


\section{Assessment}

Assessment methodology included pre-/post- written assessments. Participants completed a post- written assessment in both course format and course content. Course format assessment determined the overall appropriateness of the hybrid course format and the course content assessment evaluated change in student understanding and learning. The assessment (based on IRB approvals from NCAT) was administered to all eleven NCAT students. Participation was voluntary, as required by IRB. Three participants completed the course content survey. All participants completing the survey could see the value of the course in relation to bioengineering studies and would take the course again even if it was not required. They found the faculty and teaching assistants to be friendly, helpful and supportive of student success. Two participants were unsure of their ability to present a poster on the course content at a conference. The participants indicated that they could use course content to make contributions to ERC test investigations. The course helped the students get to know other members of the bioengineering cohort. The participants found the faculty feedback to be prompt and helpful. They indicated that they had thought about the content outside of class. Two participants agreed and one was unsure that they shared many similar opinions about the learning experiences. They indicated that they understood where they stood academically in the class. They had a better understanding of the concepts of creativity, innovation, diversity of thinking, and entrepreneurship and could see the connection among these concepts and cell biology, bioengineering, and the process of scientific discovery and inquiry. When asked about the greatest strength of the course, participants indicated that the material covered and its relation to the research as the greatest strengths. Areas for improvement included: PowerPoint presentations with too many words; the need for more discussions and homework; reducing the coverage of materials science fundamentals and increasing the focus on designs for biodegradable materials related to implants and the goals of the ERC. When asked about the hybrid course format, all participants except one agreed that they were comfortable with the delivery of course content in large-group lecture through teleconferencing. The respondents either agreed or were unsure about the feedback they received from course instructors and teacher assistants. All but one participant indicated that the course syllabus was clear and they were able to understand the learning goals for the course. Participants indicated that lecture and reading materials were properly displayed on Blackboard.

It is clear from the above data that most participants had a very positive experience in the Spring 2010 offering of the trans-ERC course on Biodegradable Metallic Alloys. However, based on the suggestions for improvements, the course would have benefited the students more if it had included even more advanced material on biodegradable materials. This may be due to it being offered to students on three geographically distant campuses with various backgrounds, i.e. materials science, bio-medical engineering, and medical school.

\section{Conclusion: Opportunities and Challenges}

The collaboration among the ERC's partner schools has enabled the true leveraging of resources, providing for rapid bootstrapping of graduate courses in an area (bioengineering and biomaterials) outside NCAT's traditional areas of instruction. The courses, in turn, advance the research agenda of the ERC by better preparing its students for successful lab work by equipping 
them with the theoretical underpinnings of their chosen discipline. Guest lectures from all partner campus and even from the global partner campus (MHH) in the case of the second course provided students as well as faculty with valuable insights on the diversity of perspectives on the same issue or topic. Students got exposed to global research as well as educational practices. Participation in national research conferences brought to life for many students the vitality, significance and vast opportunity for research and growth in a field of national strategic importance. Challenges encountered included differences in academic calendars between the three schools (one on a quarter system, two on a semester system with slightly staggered start and end dates), identification of a weekly time slot convenient to all campuses, scheduling of a televideo-enabled classroom with archiving capability and the cost of staffing such a facility, travel schedules of lead and guest instructors with active research careers outside the classroom, and the difference in exposure level to certain background information, such as biology fundamentals, among some students. The challenges were successfully overcome and the model popular enough that a third trans-ERC course, led by a researcher (Dr. Yeoheung Yun) from NCAT, was successfully offered in the Fall 2010 semester. Assessment results for that course are awaited.

As an epilogue, the success of these course added impetus to the allocation of resources for the establishment of undergraduate and masters' level degree programs in bioengineering at NCAT. The MS in Bioengineering and BS in Bioengineering started up in Fall 2010 and Spring 2011, respectively, staffed by four new faculty hires in the new Department of Chemical and Bioengineering. These will be reported on in future.

\section{Acknowledgments}

This work was principally supported by the National Science Foundation through NSF EEC-0812348: Engineering Research Center (ERC) for Revolutionizing Metallic Biomaterials at North Carolina A\&T State University, and by the State of North Carolina through cost-share funds for the ERC. Audiovisual studio and web archiving services were hosted by the Department of Bioengineering at the University of Pittsburgh. The authors also gratefully acknowledge the participation and support by fellow ERC researchers and other colleagues who gave guest lectures. At NCAT, these included guest lectures / lab visits related to nanomaterials and processing, supported through associated grants including NSF CMMI-0749028: NSEC: Center for Nano-Chemical-Electrical-Mechanical Manufacturing Systems and NSF EEC0939344: NUE - A Practical Approach to Integrating Nanotechnology Education into Undergraduate Curriculum. 